\title{
Pulmonary embolism, seasonal variations in admission to hospital, and the association of calf deep vein thrombosis with pulmonary embolism
}

\author{
Dhaher JS. Al-Habbo*, Talal M. Al-Saegh**, Mohammed K. Hammo*, Rami M. Al-Hayali* \\ *Department of Medicine, College of Medicine, University of Mosul; ** Ibn Sena Teaching Hospital, Mosul.
}

(Ann. Coll. Med. Mosul 2009; 35(2): 140-146).

Received: $18^{\text {th }}$ Feb 2009; Accepted: $4^{\text {th }}$ Oct 2009.

\begin{abstract}
Objective: To look for the presence or absence of seasonal variation of pulmonary embolism (PE). To analyze the effect of age, sex and the presence or absence of deep vein thrombosis(DVT) and its risk factors on the occurrence of PE. To analyze the ECG changes and the presence or absence of sinus tachycardia in patients with acute PE.

Method: One hundred three patients with PE were studied retrospectively, during the years 20022007 at the intensive and respiratory care unit and general medical units in Ibn-Sena Teaching Hospital.

Results: One hundred three patients with PE were studied. The age of the patients correlates significantly with the presence of PE being highest between 21-50 year of age, with p-value of $<0.001$. There were no seasonal variations in the distribution of $P E$ with $P$-value of 0.06 . Females significantly outnumbered male patients with $P$-value of 0.002 . There was no statistically significant association between the clinically evident DVT or its absence and the diagnosis of PE with p-value 0.278 . The association between the presence of PE and positive doppler ultrasound for DVT were significant with $\mathrm{p}$-value of 0.023 . There was a significant association between the presence of $P E$ and sinus tachycardia with $p$-value of $<0.001$, and negative correlation with the classical ECG changes.

Conclusion: There was no seasonal variation in the distribution of PE. There was significant association between the presence of PE and positive doppler ultrasound for DVT. Sinus tachycardias were commonly present with acute PE. We need to have more sophisticated facilities for proper diagnosis of PE.
\end{abstract}

Keywords: Pulmonary embolism, seasonal variations, deep vein thrombosis.

الخلاصة

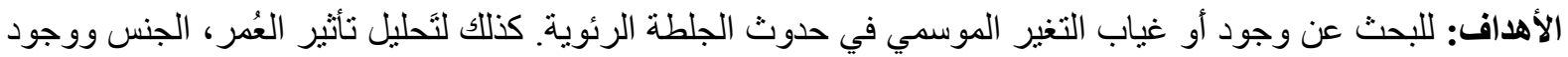

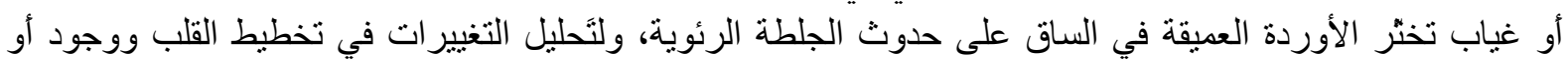

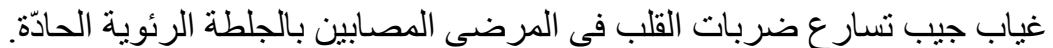

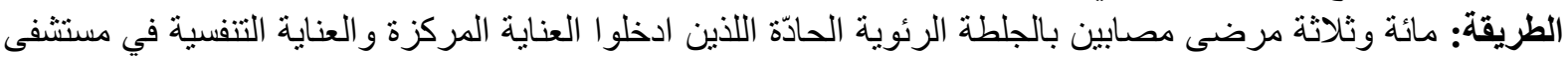

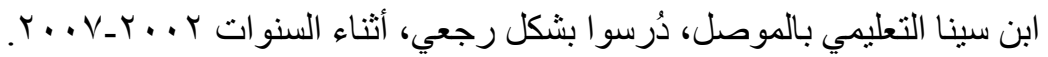

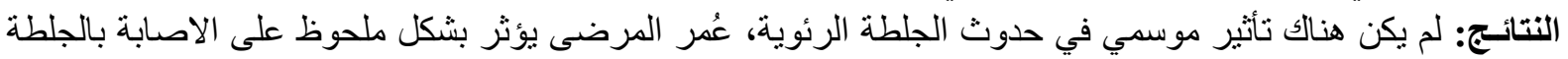

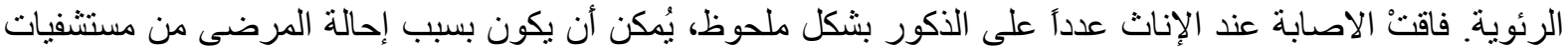

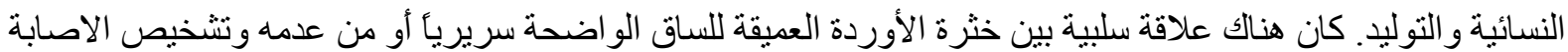




\section{بالجلطة الرئوية. الإرتباط بين الاصابة بالجلطة الرئوية وأشعة الدوبلر حول وجود خثرة الأوردة العميقة للساق ايجابي.

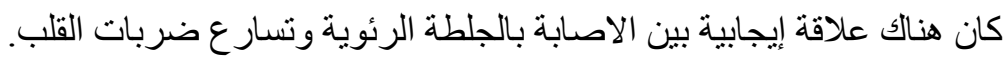

T he diagnosis of pulmonary embolism (PE) is missed more often than it is made, because PE often causes only vague and nonspecific symptoms. Pulmonary embolism is an extremely common and highly lethal condition and that is why it is a leading cause of death in all age groups. Risk factors for venous thromboembolic disease include increasing age, prolonged immobility, surgery, trauma, malignancy, pregnancy, congestive heart failure, and diseases that alter blood viscosity ${ }^{(1)}$.

Pregnancy by itself is a cause of hypercoagulability state by production of plasminogen inhibitors 1 and 2, and increasing platelet aggregation. There is increase in factors I, VII, VIII and X. Compression of the inferior vena cava by the pregnant uterus contributed to venous stasis ${ }^{(2,3)}$.

Marked increase in the number of cases of acute myocardial infarction had been reported during winter ${ }^{(4)}$. The increased serum lipids levels, plasma viscosity, fibrinogen values, factor VII:c levels, and platelet counts have been reported to increase during cold seasons which may also contribute to $P E^{(5,6)}$.

For the above reasons many pulmonologists tried to study the seasonal variation of the occurrence of PE and deep vein thrombosis (DVT). Seasonal variation for DVT is not established in many studies ${ }^{(7)}$. Pulmonary embolism on the other hand, had been reported to have seasonal variation and specifically for fatal PE as documented by postmortem diagnosis ${ }^{(8)}$.

The aim of this retrospective study is to look for the presence or absence of seasonal variation of $P E$ among patients admitted to the respiratory and intensive care units or general medical units in Ibn-Sena Teaching Hospital in Mosul. Furthermore, to analyze the effect of age, sex and the presence or absence of DVT on the occurrence of PE. Also to analyze the ECG changes and the presence or absence of sinus tachycardia in patient with acute $\mathrm{PE}$.

\section{Patients and Methods}

One hundred three patients with PE were studied retrospectively. Their age ranged $17-$ 89 year with a mean of 36.85 . Thirty six males and sixty seven females. Most of the them were admitted to the respiratory and intensive care unit or in the general medical units where they were followed by physicians working in the respiratory and intensive care unit, during the years 2002-2007. The inclusion criteria were for patients diagnosed and treated as PE with or without clinically evident DVT. The diagnosis of PE was usually done by history, clinical examination, chest $x$-ray, pulse oxymetry and electrocardiography with or without echocardiography. Furthermore, clinical signs and symptoms of deep venous thrombosis, heart rate higher than 100 beats/min, immobilization (bed rest, except to access the bathroom, for $\geq 3$ consecutive days) or surgery in the previous 4 weeks, previous objectively diagnosed deep venous thrombosis or pulmonary embolism, malignancy and pulmonary embolism as likely as or more likely than an alternative diagnosis, all the above mentioned signs or symptoms were used to predict or diagnose PE.

D-dimer test was not available for most of the times neither pulmonary angiography or ventilation perfusion lung scan. The occurrences of PE were recorded during each month of the year to look for any seasonal variation in the admission of these patients.

Statistical analysis was done by utilizing the Chi-square test and observed / expected Chisquare for the distribution of PE among patients according to age, month of admission, sex, the presence or absence of clinically evident DVT and pulse and ECG changes. Also we identify the predisposing factors for PE. 


\section{Results}

The one hundred three patients with PE were studied. They were divided into seven age groups as their age ranged from 17-89 year. The analysis of the frequency of occurrence of $P E$ according to age groups indicates that the age of the patients showed significant association with the presence of $\mathrm{PE}$, being highest between 21-50 year of age (50 female and 26 male), with $p$-value of $<0.001$ as in table (1) below.

To analyze the distribution of PE according to the seasons, the months of the years were divided into six groups because of the small number of patients per month i.e 1-2, 3-4 and so on. There were no seasonal variation in the distribution of PE with P-value of 0.06 as in table (2).

The distribution of PE according to the gender of the patients indicates that there were 36 male and 67 females, with statistically significant difference, females significantly outnumbered males with P-value of (0.002) as in table (3).

There was no significant difference in the number of patients with clinically evident DVT from those without. There was no statistically significant association between the clinically evident DVT or not and the diagnosis of PE with p-value of 0.278 as in table (4).

Doppler ultrasound of leg veins was done in 88 patients. Positive results for DVT were found in 40 patients and negative in 48 , (it was not done in 15 patients, 7 female and 8 males) and not all clinically suspected DVT were positive; the association between the presence of $\mathrm{PE}$ and positive doppler ultrasound was significant with $p$-value of 0.023 as in table (5).

There was no statistically significant association between $\mathrm{PE}$ and positive classical ECG changes (i.e. S1Q3T3), with significant difference between negative and positive ECG changes with $p$-value of $<0.001$ in favor of negative ECG changes as in table (6).

We found statistically significant association between the presence of PE and sinus tachycardia. Sinus tachycardia was present in 77 . $7 \%$ of the patients, the $p$-value was $<0.001$ as in table (7).

The male patients with pulmonary embolism mostly had orthopedic or pelvic surgery as predisposing factors as shown in table (8). Deep vein thrombosis was present alone or in association with other diseases.

The female patients with pulmonary embolism, on the other hand, mostly had cesarean section, pregnancy and pelvic surgery for gynecological and obstetric diseases as predisposing factors as shown in table (9). Deep vein thrombosis was present alone or in association with other disease.

Table (1): Distribution of pulmonary embolism in patients according to age groups.

\begin{tabular}{|l|c|c|c|c|c|}
\hline Age (year) & Female & Male & $\begin{array}{c}\text { Number of patients } \\
\text { with PE }\end{array}$ & Percentage \% & p-value \\
\hline $17-20$ & 9 & 0 & 9 & 8.7 & \\
\hline $21-30$ & 21 & 13 & 34 & 33.0 & \\
\hline $31-40$ & 22 & 7 & 29 & 28.2 & \\
\hline $41-50$ & 7 & 6 & 13 & 12.6 & $<0.001$ \\
\hline $51-60$ & 4 & 6 & 10 & 9.7 & \\
\hline $61-70$ & 2 & 3 & 5 & 4.9 & \\
\hline $71-80$ & 0 & 3 & 3 & 2.9 & \\
\hline Total & \multicolumn{7}{|l|}{103} & 100 & \\
\hline
\end{tabular}


Table (2): Distribution of pulmonary embolism according to the groups of months.

\begin{tabular}{|l|c|c|l|}
\hline Months & $\begin{array}{c}\text { Number of } \\
\text { patients with } \\
\text { of PE }\end{array}$ & $\begin{array}{c}\text { Percentage } \\
\%\end{array}$ & p-value \\
\hline $1-2$ & 9 & 8.7 & \\
\hline $3-4$ & 23 & 22.3 & \\
\hline $5-6$ & 16 & 15.5 & \\
\hline $7-8$ & 25 & 24.3 & $0.06(\mathrm{NS})$ \\
\hline $9-10$ & 13 & 12.6 & \\
\hline $11-12$ & 17 & 16.5 & \\
\hline Total & 103 & 100 & \\
\hline
\end{tabular}

Table (3): Distribution of pulmonary embolism according to the sex of patients.

\begin{tabular}{|l|c|c|c|}
\hline $\begin{array}{c}\text { Sex of } \\
\text { patients }\end{array}$ & $\begin{array}{c}\text { Number of } \\
\text { patients with } \\
\text { PE }\end{array}$ & $\begin{array}{c}\text { Percentage } \\
\%\end{array}$ & p-value \\
\hline Male & 36 & 35.0 & \multirow{2}{*}{0.002} \\
\hline Female & 67 & 65.0 & \\
\hline Total & 103 & 100 & \\
\hline
\end{tabular}

Table (4): Distribution of pulmonary embolism in patients with a positive DVT.

\begin{tabular}{|l|c|c|c|}
\hline \multicolumn{1}{|c|}{ DVT } & $\begin{array}{c}\text { Number of } \\
\text { patients } \\
\text { with PE }\end{array}$ & $\begin{array}{c}\text { Percentage } \\
\%\end{array}$ & p-value \\
\cline { 1 - 3 } $\begin{array}{l}\text { Positive } \\
\text { DVT }\end{array}$ & 46 & 44.7 & \multirow{2}{*}{0.278} \\
\cline { 1 - 3 } $\begin{array}{l}\text { Negative } \\
\text { DVT }\end{array}$ & 57 & 55.3 & \\
\hline Total & 103 & 100 & \\
\hline
\end{tabular}

Table (5): Distribution of pulmonary embolism in patients with positive Doppler.

\begin{tabular}{|l|c|c|l|}
\hline $\begin{array}{c}\text { Doppler } \\
\text { Ultrasound }\end{array}$ & $\begin{array}{c}\text { Number of } \\
\text { patients } \\
\text { with PE }\end{array}$ & $\begin{array}{c}\text { Percentage } \\
\%\end{array}$ & p-value \\
\hline $\begin{array}{l}\text { Positive } \\
\text { Doppler }\end{array}$ & 40 & 45.5 & 0.023 \\
\hline $\begin{array}{l}\text { Negative } \\
\text { Doppler }\end{array}$ & 48 & 54.5 & \\
\hline Total & 88 & 100 & \\
\hline
\end{tabular}

Table (6): Distribution of pulmonary embolism in patients with positive ECG changes.

\begin{tabular}{|l|c|c|c|}
\hline \multicolumn{1}{|c|}{$\begin{array}{c}\text { ECG } \\
\text { CHANGES }\end{array}$} & $\begin{array}{c}\text { Number of } \\
\text { patients } \\
\text { with PE }\end{array}$ & $\begin{array}{c}\text { Percentage } \\
\%\end{array}$ & p-value \\
\cline { 1 - 3 } $\begin{array}{l}\text { Positive } \\
\text { ECG }\end{array}$ & 30 & 29.1 & \multirow{2}{*}{0.001} \\
\cline { 1 - 3 } $\begin{array}{l}\text { Negative } \\
\text { ECG }\end{array}$ & 73 & 70.9 & \\
\hline Total & 103 & 100 & \\
\hline
\end{tabular}

Table (7): Distribution of pulmonary embolism and sinus tachycardia.

\begin{tabular}{|l|c|c|c|}
\hline \multicolumn{1}{|c|}{$\begin{array}{c}\text { Sinus } \\
\text { tachycardia }\end{array}$} & $\begin{array}{c}\text { Number of } \\
\text { patients } \\
\text { with PE }\end{array}$ & $\begin{array}{c}\text { Percentage } \\
\%\end{array}$ & p-value \\
\cline { 1 - 3 } $\begin{array}{l}\text { Positive Sinus } \\
\text { tachycardia }\end{array}$ & 80 & 77.7 & \multirow{2}{*}{$<0.001$} \\
\cline { 1 - 3 } $\begin{array}{l}\text { Negative Sinus } \\
\text { tachycardia }\end{array}$ & 23 & 22.3 & \\
\hline Total & 103 & 100 & \\
\hline
\end{tabular}

Table (8): Distribution of diseases Causing Pulmonary Embolism in Male Patients.

\begin{tabular}{|c|c|c|c|c|c|c|}
\hline 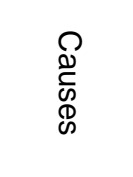 & 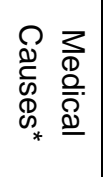 & 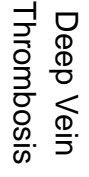 & 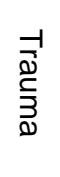 & 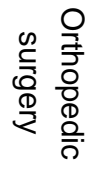 & 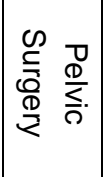 & $\begin{array}{l}-1 \\
\stackrel{0}{0} \\
\underline{1}\end{array}$ \\
\hline $\begin{array}{l}\text { Number } \\
\text { of } \\
\text { patients }\end{array}$ & 8 & 17 & 9 & 11 & 5 & 36 \\
\hline
\end{tabular}

Table (9): Distribution of diseases Causing Pulmonary Embolism in female Patients.

\begin{tabular}{|c|c|c|c|c|c|c|}
\hline 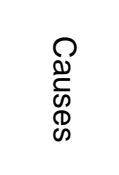 & 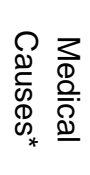 & 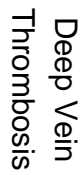 & 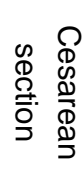 & 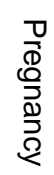 & $\begin{array}{ll}\stackrel{N}{c} & 0 \\
\stackrel{D}{D} & \frac{\mathbb{D}}{L} \\
\stackrel{\mathbb{D}}{<} & \vdots\end{array}$ & Ðో) \\
\hline $\begin{array}{c}\text { Number } \\
\text { of } \\
\text { patients }\end{array}$ & 9 & 23 & 16 & 15 & 13 & 67 \\
\hline
\end{tabular}

*Medical causes e.g. chronic obstructive airway diseases with or without respiratory failure, diabetes mellitus, chronic renal failure, and chronic cardiovascular diseases. 


\section{Discussion}

The inclusion criteria of patients with PE in this study were based on clinical findings and the recognition of predisposing factors which increase the probability of PE. The female patients mostly had pregnancy, cesarean section or pelvic surgery which were mostly gynecology and obstetrics surgery. The male patients on the other hand mostly had orthopedic or pelvic surgery. Furthermore, we do not have the proper diagnostic investigative facilities i.e. pulmonary angiography, ventilation perfusion lung scan, high resolution lung scan and even doppler echo or d-dimer test. The high resolution lung scan in our hospital were deficient of injector until 2008, the doppler ultrasound also were not available freely till the early 2008. Clinical examination of patients with $\mathrm{PE}$ and recognition of the predisposing factors remains the cornerstone of the diagnostic strategies for $\mathrm{PE}^{(9,10)}$.

The seasonal variation in the distribution of $P E$ was not clear in our patients as indicated by the results in table (2). These results may be explained by the fact that in our study, female patients outnumber the male patients, and pregnancy and its complications had no relation to particular season. Our finding is different from other studies; these studies support the seasonal variation of PE ${ }^{(11)}$. The explanation of their findings were supported by the fact that, vasoconstriction induced by cold and reduced physical activity produce a well documented reduction in blood flow in the lower limbs. Hypercoagulability state might be induced by cold weather and enhanced by respiratory tract infections during that period (6). While others claim that the seasonal variation reported by some authors may be due to the retrospective nature of the studies in which there is no real indication of the "main diagnosis" on discharge of these reported patients. Since some investigators question the whole issue and claim that, "patients as well as doctors take vacations in summer, resulting in a significant decrease in nonurgent surgical activities, admissions, and, likely, surgery-related complications; similarly, summer months have been shown to result in a $20 \%$ decrease in admissions for pneumonia and other emergency respiratory diseases" ${ }^{(12)}$.

The distribution of PE according to the gender of the patients in this study indicates that there were more female than male patients, with statistically significant difference between them, with P-value of $(0.002)$ as in table (3). This result is different from other studies where they report that males are more commonly affected than females ${ }^{(13,14)}$. The only explanation of our finding may be due to the fact that a large number of our patients came from gynecological and obstetric hospitals because they do not have proper intensive care units.

The frequency of PE according to age groups indicates that the highest incidence of PE were between 21-50 year of age. In hospitalized elderly patients, PE is commonly missed and often is the cause of death. This speculation may explain the small number of patients with $P E$ in the age group of 61-80 year of age. The analysis of our results however, shows that the age of the patients correlates significantly with the presence of PE with $p$-value of $<0.001$ as in table (1). Our finding is more or less (although not clearly defined) is similar to other studies where they found that for each 10-year increase in age, the incidence of $P E$ is doubled ${ }^{(13,14)}$.

In this study deep vein thrombosis was clinically positive in $44.7 \%$ and negative in $55.3 \%$ of the patients with PE, with no statistically significant association between clinically present or clinically absent DVT with $p$-value of 0.278 . The presence or absence of clinical DVT does not represent the real incidence of DVT as venous thrombosis may occur anywhere in the body. Deep vein thrombosis in the calf, when considered alone, has low predictive value $(15 \%)$ for PE ${ }^{(15)}$.

Furthermore it was found that few patients with PE will have evident DVT so they even do not recommend doppler ultrasound for DVT if it is clinically absent during the investigation of suspected PE ${ }^{(16)}$.

The number of patients with positive doppler ultrasound for DVT was found in $45.5 \%$ of the patients and negative in $54.5 \%$, though it was not done in 15 patients ( 7 female and 8 males) 
and not all clinically suspected DVT had positive doppler ultrasound. The association between the presence of $\mathrm{PE}$ and positive doppler ultrasound was statistically significant with $p$-value of 0.023 . The accuracy of doppler ultrasound depends on the operator and cannot distinguish between new clot or old one. Furthermore, it is not sensitive in detecting DVT in small vessel of the calf or in detecting DVT in the presence of obesity or significant edema as in patients with trauma.

In a study of 41 patients with positive abnormalities on pulmonary angiography, the results of leg venography were normal in 12 patients ${ }^{(17)}$. There are many studies to estimate the prevalence of DVT with PE which indicates wide discrepancies ranging from 10 to $70 \%$ in pulmonary angiography based studies and 25 to $93 \%$ in VIQ based studies, and in meta-analysis study of the prevalence of DVT in patients suspected PE was $18 \%$ and in proven $\mathrm{PE} 36-45 \%{ }^{(16,18,19,20)}$.

There was no statistically significant association between PE and the finding of a positive classical ECG changes. The number of patients with negative classical ECG changes outnumbered those with a positive classical ECG changes. The number of patients with PE and negative classical ECG changes was statistically significant with $p$ value of $<0.001$ in favor of negative ECG changes. The abnormal classical ECG changes in patients with $P E$ is rather nonspecific and its absence does not rule out the diagnosis of $\mathrm{PE}{ }^{(21)}$.

Clinical examination of most of the patients in this study revealed sinus tachycardia with a positive correlation between the presence of $\mathrm{PE}$ and sinus tachycardia. This finding is consistent with other studies where they found that in PE the most frequent clinical signs were tachypnea and tachycardia ${ }^{(22,23)}$.

Rodger $\mathrm{M}$ et al, from Canada found in 212 consecutive patients referred for $\mathrm{V} / \mathrm{Q}$ or Pulmonary angiogram for suspected PE only 2 abnormalities (tachycardia and incomplete RBBB) significantly more prevalent in PE positive than $P E$ negative patients ${ }^{(24)}$. In another study of patients with positive or negative $\mathrm{PE}$, they found sinus tachycardia present in (39\% vs 24\%) atrial tachy arhythmias ( $15 \%$ vs $4 \%)$, Q3 (40\% vs $26 \%)$ and Q3T3 (8\% vs1\%) ${ }^{(25)}$.

Furthermore, other investigators in an observational study have compared 49 patients with pulmonary embolism with similar number of people without PE. They found sinus tachycardia in $(18.8 \%$ vs $11.8 \%)$, incomplete RBBB (4.2\% vs 0\%), S1Q3T3 $\left(2.1 \%\right.$ vs $0 \%$ ) and S1Q3 (0 vs 0 ) ${ }^{(26)}$.

All the previously mentioned studies support our findings and add more insight to the usefulness of the ECG recording and the monitoring of pulse rate in patients with suspected PE.

\section{Conclusion}

There were no seasonal variations in the distribution of PE. PE being highest between 21-50 year of age with female patients significantly outnumbered males. There was strong association between the presence of PE and positive doppler ultrasound for DVT. Sinus tachycardias were commonly present with acute PE. We need to have more sophisticated facilities for proper diagnosis of PE.

\section{References}

1. Heit JA, O'Fallon WM, Petterson TM, Lohse CM, Silverstein MD, Mohr DN, et al. Relative impact of risk factors for deep vein thrombosis and pulmonary embolism: a population-based study. Arch Intern Med 2002;162:1245-8.

2. Becker RC, Fintel DJ, Green D. Anti thrombotic therapy. $3^{\text {th }}$ ed. Caddo: Professional Communications 2004; 3553, 181-94.

3. Eriksen L, Pachler JH. Venous thrombectomy in pregnancy. A follow-up study. Ugeskr Laeger. 1999;161: 5683-6.

4. Spencer FA, Goldberg RJ, Becker RC, et al. Seasonal distribution of acute myocardial infarction in the Second National Registry of Myocardial Infarction. J Am Coll Cardiol. 1998; 31:1226-1233.

5. Neild PJ, Syndercombe-Court D, Keatinge WR, Donaldson GC, Mattock M, Caunce $M$. Cold-induced increases in erythrocyte count, plasma cholesterol and plasma 
fibrinogen of elderly people without a comparable rise in protein $\mathrm{C}$ or factor $\mathrm{X}$. Clin Sci. 1994;86:43-48.

6. Woodhouse PR, Khaw KT, Plummer $M$, Foley A, Meade TW. Seasonal variations of plasma fibrinogen and factor VII activity in the elderly: winter infections and death from cardiovascular disease. Lancet. 1994;343:435-439.

7. Bounameaux H, Hicklin L, Desmarais S. Seasonal variation in deep vein thrombosis. BMJ 1996; 312: 284-285.

8. Allan TM, Douglas AS. Seasonal variation in deep vein thrombosis. BMJ 1996; 312: 1227.

9. Miniati $M$, Prediletto R, Formichi $B$, et al. Accuracy of clinical assessment in the diagnosis of pulmonary embolism. Am J Respir Crit Care Med. 1999;159:864-871.

10. Perrier A, Miron M-J, Desmarais S, et al. Combining clinical evaluation and lung scan to rule out suspected pulmonary embolism. Arch Intern Med. 2000;160:512516.

11. Allan TM, Douglas AS. Seasonal variation in deep vein thrombosis. BMJ 1996; 312: 1227.

12. Saynajakangas $P$, Keistinen $T$, Tuuponen $T$. Seasonal fluctuations in hospitalisation for pneumonia in Finland. Int $\mathrm{J}$ Circumpolar Health 2001; Jan 60(1):34-40.

13. Anderson FA Jr, Wheeler HB, Goldberg $\mathrm{RJ}$, et al. A population-based perspective of the hospital incidence and case-fatality rates of deep vein thrombosis and pulmonary embolism: the Worcester DVT Study. Arch Intern Med1991;151:933-938.

14. Silverstein MD, Heit JA, Mohr DN, Petterson TM, O'Fallon WM, Melton LJ III. Trends in the incidence of deep vein thrombosis and pulmonary embolism: a 25-year population-based study. Arch Intern Med 1998;158:585-593.

15. Wells PS, Anderson DR, Bormanis J, Guy $F$, Mitchell $M$, Gray $L$, et al. Value of assessment of pretest probability of deepvein thrombosis in clinical management. Lancet 1997;350:1795-98.

16. Beecham RP, Dorfman GS, Spearman $M P$, et al. Is bilateral lower extremity compression sonography useful and cos- effective in the evaluation of suspected pulmonary embolism? AJR 1993; 161: 1289-92.

17. Hull RD, Hirsh J, Carter CJ, et al. Pulmonary angiography, ventilation lung scanning, and venography for clinically suspected pulmonary embolism with abnormal perfusion lung scan. Ann Intern Med 1983;98:891-899.

18. Christiansen $F$, Kellerth $T$, Andersson $T$, Ragnarsosn $A$ and Hjortevang $F$. Ultrasound at scintigraphic "intermediate probability of pulmonary embolism" Acta Radiol 1996;37:14-7.

19. Tukstra f, Kuijer PMM, van Beek EJR, Branjes DPM, ten Cate JW and Buller HR. Diagnostic utility of ultrasonography of leg veins in patients suspected of having pulmonary embolism. Ann Intern Med 1997;126:775-81.

20. van Rossum $A B$, van Houwelingen $H C$, kieft GJ and PM Pattynama.prevalance of deep vein thrombosis in suspected and proven pulmonary embolism: metaanalysis. BJR 1998;71:1260-1265.

21. Stein PD, Terrin ML, Hales CA, et al. Clinical, laboratory, roentgenographic, and electrocardiographic findings in patients with acute pulmonary embolism and no pre-existing cardiac or pulmonary disease. Chest 1991;100:598-603.

22. Stein PD, Saltzman HA, Weg JG. Clinical characteristics of patients with acute pulmonary embolism. Am. J. Cardiol. 1991; 68: 1723-1724.

23. Stein PD, Terrin ML, Hales CA, et al. Clinical laboratory, roentgenographic, and electrocardiographic findings in patients with acute pulmonary embolism and no pre-existing cardiac or pulmonary disease. Chest 1991;100:598-603.

24. Rodger M, Makropolous D, Turek M, et al. Diagnostic value of the Electrocardiogram in Suspected Pulmonary Embolism. American Journal of Cardiology 2000; 86: 807-809.

25. Sinha N, Yalamanchili K, Sukhija R, et al. Role of the 12-lead electrocardiogram in diagnosing pulmonary embolism. Cardiol in review 2005;13:46-9.

26. Richman PB, Louti $\mathrm{H}$, Lester $\mathrm{SJ}$, et al. Electrocardiographic findings in Emergency Department patients with pulmonary embolism. J Emerg Med 2004; 27:121-6. 